\title{
Contraceptive practices in HIV seropositive females in Ireland
}

\author{
D Murphy MB ${ }^{1}$, M Lynch MB MRCPI ${ }^{1}, \mathbf{N}$ Desmond MB MRCPI ${ }^{2}$ and \\ F M Mulcahy MD FRCPI ${ }^{1}$ \\ ${ }^{1}$ Department of Genitourinary Medicine, St James's Hospital, Dublin 8, Ireland and \\ Patrick Clements Clinic, Central Middlesex Hospital, London NW10 7NS, UK
}

\begin{abstract}
Summary: A questionnaire was administered to a cohort of 130 HIV seropositive women attending the Department of Genitourinary Medicine, St James's Hospital, Dublin, in order to establish their current contraceptive practices. Forty $(42 \%)$ of the sexually active women did not use reliable contraception; 55 (57\%) used a method reliable in fertility control only, and $21(22 \%)$ used a method reliable in terms of both partner and congenital transmission. The intravenous drug users were less likely to use reliable contraception, $9(39 \%)$, in comparison to the heterosexual group $14(70 \%), \mathrm{P}<0.05$. The heterosexual group were more likely to use condoms consistently, 7 (35\%) in comparison to one (4\%) of intravenous drug users, $\mathrm{P}<0.02$. Nineteen children, 3 borne to heterosexual mothers and 16 borne to intravenous drug-using mothers were HIV seropositive after 18 months.
\end{abstract}

Keywords: HIV, female, contraception

\section{INTRODUCTION}

Current predictions suggest that the heterosexual and congenital modes of HIV transmission will be of prime importance in the future ${ }^{1,2}$. Up until December 1991, 1188 people had tested HIV positive in Ireland; $39.5 \%$ of all cases are IV drugrelated and $9 \%$ are heterosexual. This compares to 1986 where there were no heterosexual cases. The number of children HTV seropositive at birth for the same period is $78^{3}$.

HIV seropositive women will need to be targeted in terms of prevention of spread of the virus. On this basis, all newly diagnosed carriers of HTV attending the Department of Genitourinary Medicine are instructed by experienced counsellors on safe sexual practices.

Goedert ${ }^{4}$ has outlined strategies based on abstention as a primary aim, but where this is not acceptable numerous laboratory and epidemiological studies have confirmed the reliability of the condom, when used properly, in preventing virus transmission ${ }^{5,9}$.

This study assesses the contraceptive practices of a cohort of Irish HIV seropositive women who have been fully counselled on safe sexual practices.

\section{PATIENTS AND METHODS}

All HIV seropositive women attending the Department of Genitourinary Medicine, St James's Correspondence to: Dr D Murphy, Genitourinary Medicine, St James's Hospital, Dublin 8, Ireland
Hospital, Dublin, between July 1991 and December 1991 were included in the study. One hundred and thirty of a cohort of 150 women completed a questionnaire designed to enquire about current marital status, parity, number of HIV seropositive children, sexual activity, intravenous drug-using activity, HIV status of regular partner and contraceptive usage.

Age, mode of HIV acquisition and duration of known HIV seropositive status were established from the records. The patients were classified according to the Centers for Disease Control, (CDC), Atlanta, 1987, revision of case definition for $\operatorname{AIDS}^{10}$.

There was a total of 130 women whose median age was 27 years (mean 25, range 20-36). The presumed method of HIV acquisition was intravenous drug use in $109(84 \%)$ of the 130 women and heterosexual contact in $21(16 \%)$. The range in duration of 'known HIV seropositive status was between 2 months and 7 years, the mean being 3 years.

There were 77 CDC 11 patients, 31 CDC 111 patients and 22 CDC IV patients.

\section{RESULTS}

\section{Marital status and children}

Marital status frequently changed since first being diagnosed HIV seropositive, but at the time of questioning, 90 women were single, 19 were married, 16 were separated, 4 were widowed and one woman was divorced. 
Table 1. Children of HIV seropositive mothers

\begin{tabular}{|c|c|c|c|}
\hline $\begin{array}{l}\text { Risk category for } \\
\text { HIV acquisition }\end{array}$ & $\begin{array}{l}\text { No. } \\
\text { mothers }\end{array}$ & $\begin{array}{l}\begin{array}{l}\text { No. } \\
\text { children }\end{array} \\
\text { che }\end{array}$ & $\begin{array}{l}\text { No. HIV + after } \\
18 \text { months }\end{array}$ \\
\hline Hetero & 15 & 33 & 3 \\
\hline Ex-IVDU & 51 & 121 & 12 \\
\hline Current IVDU & 27 & 52 & 4 \\
\hline Total & 93 & 206 & 19 \\
\hline
\end{tabular}

There were 37 nulliparous women; 93 women were parous or multiparous, the highest parity being $7^{+2}$. Of the parous women, 16 had had spontaneous abortions and 2 had had terminations of pregnancy. Three women were currently pregnant and a total of 19 children were HIV seropositive 18 months after birth (Table 1).

\section{Sexual activity and partner status}

Thirty-five (27\%) of the women were not currently sexually active by virtue of ill health, no current partner, partner imprisonment or self imposed abstinence. Of the 95 women who were sexually active, $84(65 \%)$ stated that they had one regular partner only of whom $35(38 \%)$ had not been tested or denied testing and $17(20 \%)$ had been tested and were currently HIV negative. The number of sexual partners of the other $11(8 \%)$ women ranged from 2 to greater than 10 with 6 women admitting to prostitution.

\section{Contraceptive usage}

Of the non-sexually. active women, one used a combined oral contraceptive for regulation of the menses and one had an intrauterine contraceptive device (IUCD) in situ. Of the currently sexually active women $55(57 \%)$ used a reliable method of contraception in terms of fertility control and 21 $(22 \%)$ used a method reliable in terms of both heterosexual and vertical transmission (Table 2).

A hysterectomy was indicated for one woman who had cervical malignancy and the husband of one patient was confirmed to be sterile. Six patients were using condoms in addition to another method of contraception.

Table 2. Contraceptive usage in sexually active HIV seropositive women

\begin{tabular}{|c|c|c|c|}
\hline Contraceptive & $\begin{array}{l}\text { Risk group } \\
\text { Hetero }\end{array}$ & Ex-IVDU & $\begin{array}{l}\text { Current } \\
\text { IVDU }\end{array}$ \\
\hline Condom & 7 & 13 & 1 \\
\hline Oral contraceptive pill & 5 & 11 & 2 \\
\hline Depoprovera & 2 & 6 & 2 \\
\hline $\begin{array}{l}\text { Intrauterine } \\
\text { contraceptive device }\end{array}$ & 1 & 1 & 3 \\
\hline Tubal ligation & 0 & 4 & 1 \\
\hline Hysterectomy & 0 & 1 & 0 \\
\hline Male sterilization & 1 & 0 & 0 \\
\hline None & 6 & 20 & 14 \\
\hline Two methods & 2 & 4 & 0 \\
\hline Total & 20 & 52 & 23 \\
\hline
\end{tabular}

Table 3. Risk category for HIV acquisition

$$
\begin{aligned}
& \text { Hetero Ex-IVDU Current } P \text { value } \\
& \begin{array}{llllllll}
\text { No. contraception } & * 6 & (30 \%) & 20 & (38 \%) & * 14 & (61 \%) & P<0.05
\end{array} \\
& \begin{array}{lllllcll}
\text { Fertility control only } & 14 & (70 \%) & 32 & (61 \%) & 9 & (39 \%) & \\
\text { Condoms } & * 7 & (35 \%) & 13 & (25 \%) & * 1 & (4 \%) & P<0.02
\end{array}
\end{aligned}
$$

There was a statistically significant difference between the contraceptive practices of the heterosexual group and the current intravenous drug users. The intravenous drug users were likely to use reliable contraception, $9(39 \%)$ in comparison to the heterosexual group $14(70 \%) \mathrm{P}<0.05$.

The heterosexual group were more likely to use condoms consistently, 7 (35\%) in comparison to one (4\%) of intravenous drug users, $P<0.02$. There was no statistical difference between the contraceptive practices of the ex-intravenous drugusers when compared to the heterosexual group (Table 3).

\section{DISCUSSION}

This group of HTV seropositive women demonstrate a poor uptake of effective contraceptive measures in limiting the vertical and heterosexual transmission of the human immunodeficiency virus. With no cure for HTV infection, to date, the main strategy is health promotion and disease prevention by effective education means.

Various strategies have been proposed in general terms ${ }^{11-12}$. Goedert is more specific in advocating the elimination rather than the reduction of risky behaviour ${ }^{4}$. The uptake of this advice in Irish seropositive women was poor despite expert counselling. The overall use of contraception was low and the consistent use of condoms was also disappointing (22\%), in view of numerous laboratory and epidemiological studies which confirm their reliability in preventing virus transmission $^{5-9}$.

It is worthwhile noting that Irish legislation may contribute to limiting contraceptive availability. Condoms can only be sold by registered pharmacists or Family Planning Clinics and only to individuals of 17 years or over. The oral contraceptive pill was only first licensed for contraceptive purposes in 1980. Efforts are made to overcome these difficulties by providing condoms free of charge in the Department of Genitourinary Medicine.

Drug users are not necessarily representative of all HIV infected women. They tend to change to safe drug-using practices but not to safe sexual behaviour ${ }^{13}$. This is borne out by the poor uptake of safe contraception in the study group, the majority of whom have been IV drug users, but most particularly in the current IV drug-using group. It must not be forgotten that the source of infection can still be heterosexual and the social 
problems of this group should not overshadow the 'need to avoid disease spread by the sexual route.

The number of pregnancies and children borne to these women is a major concern. Some studies suggest that the decision to have a child was unaffected by factors relating to HIV infection including the woman's health and a previously infected child ${ }^{14}$. This may be more of a problem in the Irish context, where there is a high national birth rate (14.9 per 1000 population in 1991) and where social welfare payments and housing provision are dictated by the number of children in a family.

It can be concluded from this analysis that our current patient education methods are insufficient in reliably controlling the heterosexual and congenital transmission of HIV in this patient group.

\section{References}

1 Department of Health/Welsh Office. Short-term prediction of HIV infection and AIDS. Report of a working group. London: HMSO, 1988

2 Chin J. Current and future dimensions of the HIV/AIDS pandemic in women and children. Lancet 1990;336:221-4

3 Department of Health, Republic of Ireland. Statistics from 1188 HIV seropositive cases up to December 1991

4 Geodert J. Sounding Board. What is safe sex? N Engl J Med 1987;316:1339-41

5 Valdiserri RO, Arena VC, Proctor D, Bonati FA. The relationship between women's attitudes about condoms and their use; implications for condom promotion programmes. Am J Public Health 1989;79:499501

6 Conant M, Hardy D, Sernatinger J, Spicer D, Levy JA. Condoms prevent transmission of AIDS associated retrovirus (letter). JAMA 1986; 255:1706

7 Ngugi EN, Plummer FA, Simonsen JN, et al. Prevention of transmission in Africa. Effectiveness of condom promotion and health education among prostitutes. Lancet 1988;ii:887-90

8 Van de Perre P, Jacobs D, SprecherGoldberger S. An efficient barrier against sexual transmission of AIDS related viruses. AIDS 1987;1(1):30-3

9 Hooykaas C, Van der Pligt J, Van Doornum GJ, Van der Linden MM, Coutinha RA. Heterosexual risk for HIV. Differences between private and commercial partners in sexual behaviour and condom use. AIDS 1989;3(8):525-32

10 Centers for Disease Control, Atlanta, Georgia. Revision of case definition for AIDS, for surveillance purposes. MMWR 1987;36:No 15

11 Friedland GH, Klein RS. Transmission of human immunodeficiency virus. N Engl J Med 1987;317:1125-35

12 Hearst N, Hulley SB. Preventing the heterosexual spread of AIDS. JAMA 1988;259:2428-32

13 Hart G. Presentation at IVth International Conference on AIDS, Stockholm 1988

14 Selwyn PA, Carter RJ, Schoenbaum EE, et al. Knowledge of HIV antibody status and decisions to continue or terminate pregnancy among intravenous drug users. JAMA 1989; 261:3567-71

(Accepted 25 October 1992) 